\title{
Prognostic implications of mucinous histology in stage III colon cancer with the receipt of adjuvant chemotherapy
}

\author{
Feng $\mathrm{Yu}^{1}$, Luqiao Huang ${ }^{1}$, Feng Shen ${ }^{1}$, Shuang $\mathrm{Wu}^{1}$, Jian $\mathrm{Chen}^{2}$ \\ ${ }^{1}$ Department of Colorectal Surgery, ${ }^{2}$ Department of Gastrointestinal Surgery, Tongde Hospital of Zhejiang Province, Hangzhou, China \\ Contributions: (I) Conception and design: S Wu, J Chen; (II) Administrative support: F Yu, L Huang; (III) Provision of study materials or patients: \\ F Yu, L Huang, F Shen; (IV) Collection and assembly of data: F Shen, S Wu; (V) Data analysis and interpretation: F Yu, L Huang; (VI) Manuscript \\ writing: All authors; (VII) Final approval of manuscript: All authors. \\ Correspondence to: Jian Chen. Department of Gastrointestinal Surgery, Tongde Hospital of Zhejiang Province, 234 Gucui Road, Hangzhou 310012, \\ China. Email: jimmychen7802@126.com.
}

\begin{abstract}
Background: There is still a debate about the survival benefit of chemotherapy in stage III mucinous colon cancer, we then conduct a comprehensive assessment of the efficacy of adjuvant chemotherapy in this population.

Methods: The data used in the current study were extracted from the Surveillance, Epidemiology and End Results (SEER) database. Chi-squared $\left(\chi^{2}\right)$ test was used to compared patient characteristics according to the histology. The outcome of the survival analysis used in the current study was cancer-specific survival (CSS). Univariable and multivariable analyses were carried out using the Cox proportional hazards regression models to evaluate the prognostic characteristics associated with CSS of colon cancer. And the risks of mortality were presented as hazard ratios (HRs) with 95\% confidence intervals (CIs).

Results: A total of 68,976 patients diagnosed with stage III colon cancer were included in our analyses, including mucinous adenocarcinoma (MAC, $\mathrm{N}=6,592)$ and non-mucinous adenocarcinoma (NMA, $\mathrm{N}=62,384)$. In NMA, the receipt of chemotherapy had $46.0 \%$ independently decreased risk of colon cancerspecific mortality compared to non-chemotherapy group ( $\mathrm{HR}=0.540,95 \% \mathrm{CI}$ : $0.523-0.558, \mathrm{P}<0.001)$. In MAC, the receipt of chemotherapy had $37.7 \%$ independently decreased risk of colon cancer-specific mortality compared to non-chemotherapy group (HR =0.623, 95\% CI: 0.566-0.685, $\mathrm{P}<0.001$ ).

Conclusions: MAC was associated with worse prognosis and was less responsive to chemotherapy compared with NMA in stage III colon cancer. However, stage III mucinous colon cancer still need to be treated with chemotherapy because of the significant survival benefit and specialized treatment plans for MAC were quite necessary in the future.
\end{abstract}

Keywords: Stage III; mucinous; colon cancer; adjuvant chemotherapy; survival

Submitted Mar 21, 2020. Accepted for publication Aug 18, 2020.

doi: 10.21037/jgo-20-160

View this article at: http://dx.doi.org/10.21037/jgo-20-160

\section{Introduction}

Colon cancer is one of the most frequent types of malignancies in clinical practice (1). As everyone knows that the most common histological type in colon cancer is adenocarcinoma, among which mucinous adenocarcinoma (MAC) is a distinct subtype and consisted of more than $50 \%$ extracellular mucin (2). It was reported that MAC occupied $10-20 \%$ of colorectal cancer patients, with a lower rate in Asian countries but a higher rate in Western countries (3-7). In addition, MAC was reported to have distinct clinicopathological and genetic features (including advanced stages, microsatellite instability, BRAF mutation, and proximal colon) (7-10).

However, the prognostic value of MAC in colon cancer is still controversial. On the one hand, some researchers believed that MAC was associated with lower survival rate 


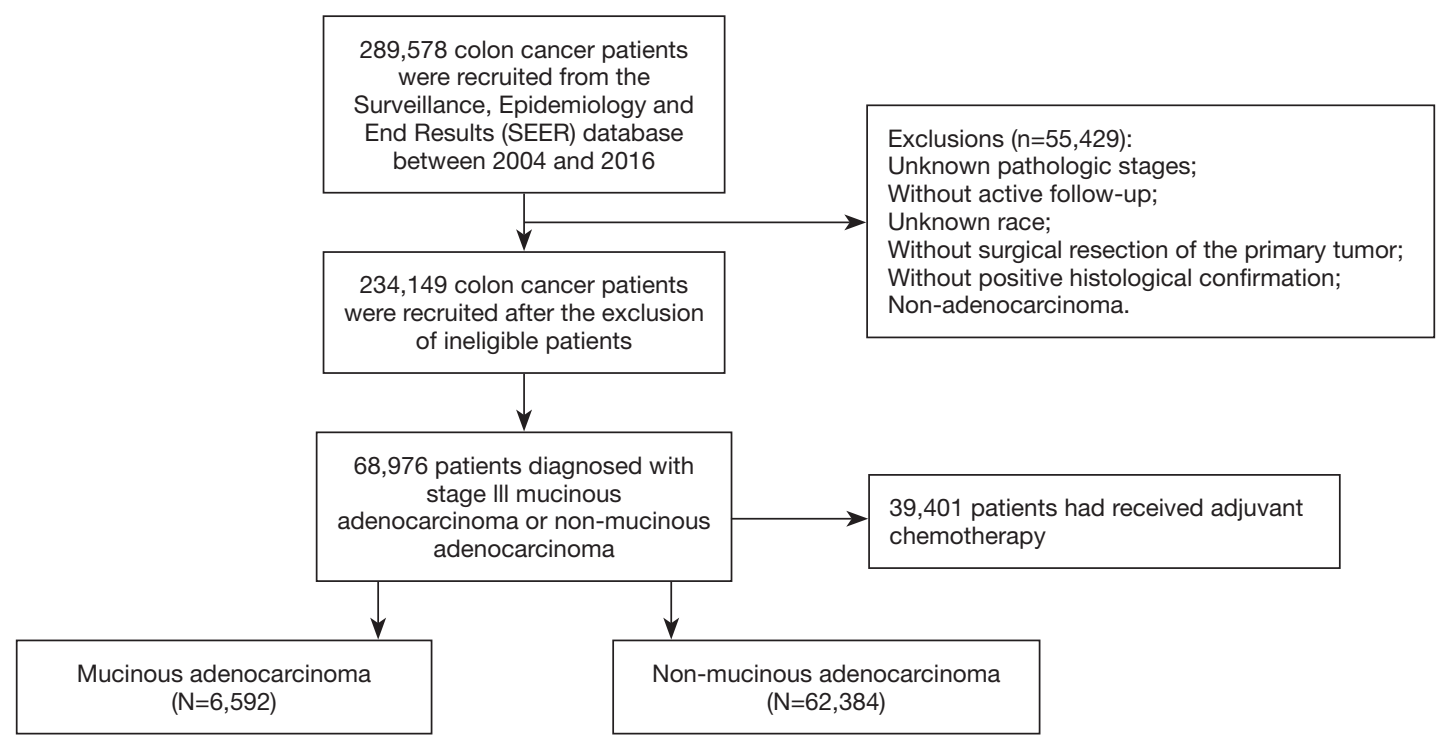

Figure 1 Patient selection flowsheet.

$(11,12)$. On the other hand, others reported that MAC was not independently associated with the prognosis of colon cancer (13).

More importantly, there had been considerable debate with regards to the survival benefit of chemotherapy (CT) in stage III MAC. In stage III colon non-mucinous adenocarcinoma (NMA), the efficacy of adjuvant CT had been confirmed for a long time (14). In stage III mucinous colon cancer, some studies had shown that stage III MAC had worse chemosensitivity as compared with NMA $(3,15,16)$, however, there were also some studies which suggested that there was no significant difference in the survival benefit of adjuvant CT between MAC and NMA $(12,17)$. In addition, National Comprehensive Cancer Network (NCCN) did not take the presence of MAC into consideration when it came to the colon cancer treatment decisions (18).

Moving from this background, we decided to carry out a large population-based study to conduct a comprehensive assessment of the efficacy of adjuvant CT in stage III mucinous colon cancer. Combined with previous findings, we believed our study would add the body of evidence to guide the clinical treatment of stage III mucinous colon cancer.

We present the following article in accordance with the STROBE reporting checklist (available at http://dx.doi. org/10.21037/jgo-20-160).

\section{Methods}

\section{Patients}

Given the rarity of mucinous colon cancer, a large cancer database was needed for this study. Sponsored by the US National Cancer Institute and established in 1973, the Surveillance, Epidemiology and End Results (SEER) database was the most authoritative source including the information of cancer incidence, patient survival, clinicopathological features, treatment and outcome data in the United States (https://seer.cancer.gov/). SEER currently collects and publishes cancer-related data annually from SEER-participating areas covering approximately $28 \%$ of the U.S. population (19). The study was conducted in accordance with the Declaration of Helsinki (as revised in 2013). This was a study using de-identified data from the SEER database. Ethical approval by the ethical committee of the Tongde Hospital of Zhejiang Province was waived based on our institutional policy. The SEER database is a free database, the data released by the SEER database did not require informed consent of patients.

As shown in Figure 1, the data used in the current study were extracted from the SEER database. At first, a total of 289,578 colon cancer patients were recruited between 2004 and 2016. Then, patients meeting the following criteria were excluded from our analyses: (I) unknown pathologic stages; (II) without active follow-up; (III) unknown race; 
(IV) without surgical resection of the primary tumor; (V) without positive histological confirmation; (VI) nonadenocarcinoma.

According to the 8th edition of Tumor Node Metastasis (TNM)/American Joint Committee on Cancer (AJCC) staging system, node-negative patients with tumor deposit were restaged as N1. Finally, only patients diagnosed with stage III MAC or NMA were included in our analyses. In the present study, the following variables were identified from the SEER database: $\mathrm{T}$ stage, $\mathrm{N}$ stage, age, race, gender, tumor location, tumor grade, the receipt of CT and histological subtypes.

\section{Statistical analysis}

Chi-squared $\left(\chi^{2}\right)$ test was used to compared patient characteristics according to the histology. The outcome of the survival analysis used in the current study was cancerspecific survival (CSS). Survival curves were generated using Kaplan-Meier method for the comparison of CSS difference that was tested using the log-rank test. Univariable and multivariable analyses were carried out using the Cox proportional hazards regression models to evaluate the prognostic characteristics associated with CSS of colon cancer. The risks of mortality were presented as hazard ratios (HRs) with 95\% confidence intervals (CIs). Variables with $\mathrm{P}$ values less than 0.20 in the univariate Cox regression analyses were then included in multivariate regression analyses. In addition, propensity score matching (PSM) was used to provide an estimate of the likelihood that the patient would receive adjuvant CT. A P value less than 0.05 was considered statistically significant. Statistical analyses were performed with SPSS, version 22.0 (IBM Corporation, Armonk, NY, USA).

\section{Results}

\section{Baseline cohort characteristics}

As shown in Figure 1, a total of 68,976 patients diagnosed with stage III colon cancer were included in our analyses, including MAC $(\mathrm{N}=6,592)$ and NMA $(\mathrm{N}=62,384)$. The median follow-up time of all the patients was 41 months. Among them, 39,401 (57.1\%) patients had received adjuvant CT. The median age of the whole cohort was 69 years, and $48.3 \%(\mathrm{~N}=33,314)$ of them were male. More than a half of the patients were diagnosed with N1 stage $(67.2 \%)$, and N2 stage only occupied $32.8 \%$.
The demographics and clinicopathological characteristics of all the patients were presented in Table 1. MAC was more inclined to be associated with higher $\mathrm{T}$ stage $(\mathrm{P}<0.001)$, higher $\mathrm{N}$ stage $(\mathrm{P}<0.001)$, older age $(\mathrm{P}<0.001)$, white race $(\mathrm{P}<0.001)$, right-side colon cancer $(\mathrm{P}<0.001)$ and higher tumor grade $(\mathrm{P}<0.001)$, indicating that MAC was correlated with worse clinicopathological features compared with NMA. However, no significant differences were seen between MAC and NMA with regards to gender $(\mathrm{P}=0.063)$ and the receipt of $\mathrm{CT}(\mathrm{P}=0.352)$.

\section{The efficacy of CT in MAC and NMA}

First, as shown in Figure $2 \mathrm{~A}$, we used Kaplan-Meier method to evaluate the survival benefit of CT in the whole cohort, and the survival curves showed that CT group had significantly improved CSS compared with non-CT group (5-year CSS rates: $64.4 \%$ vs. $77.5 \%, \mathrm{P}<0.0001$ ). For the histological subtypes of colon cancer, NMA group had significantly improved CSS compared with MAC group (5-year CSS rates: $72.7 \%$ vs. $67.9 \%, \mathrm{P}<0.0001$, Figure 2B). In addition, the results of Cox analyses also showed that MAC was independently associated with $5.6 \%$ increased risk of cancer-specific mortality ( $\mathrm{HR}=1.056,95 \% \mathrm{CI}$ : $1.005-1.109, \mathrm{P}=0.030$, Table S1) and the receipt of CT was independently associated with $45.1 \%$ decreased risk of colon cancer-specific mortality ( $\mathrm{HR}=0.549,95 \% \mathrm{CI}$ : 0.532-0.567, $\mathrm{P}<0.001$, Table S1).

We then aimed to evaluate the efficacy of CT in MAC and NMA, respectively. In Figure 3A, the receipt of CT was associated with $13.6 \%$ increased 5 -year CSS rate compared to non-CT group in NMA (5-year CSS rates: $78.1 \%$ vs. $64.5 \%, \mathrm{P}<0.0001)$; in MAC, however, the receipt of CT had only $8.2 \%$ increased 5 -year CSS rate compared to non-CT group (5-year CSS rates: $71.3 \%$ vs. 63.1\%, $\mathrm{P}<0.0001$; Figure 3B).

To validate the above results from Kaplan-Meier analyses, variables including $\mathrm{T}$ stage, $\mathrm{N}$ stage, age, race, gender, tumor location, tumor grade and the receipt of CT were included in univariate Cox proportional hazards regression models, and variables with $\mathrm{P}$ values less than 0.20 in the univariate Cox regression analysis were then included in multivariate analyses. In NMA, T stage $(\mathrm{P}<0.001), \mathrm{N}$ stage $(P<0.001)$, age $(P<0.001)$, race $(P<0.001)$, tumor location $(\mathrm{P}<0.001)$, tumor grade $(\mathrm{P}<0.001)$ and the receipt of $\mathrm{CT}(\mathrm{P}<0.001)$ were subsequently incorporated into the multivariate analysis, which showed that the receipt of CT had $46.0 \%$ independently decreased risk of colon cancer- 
Table 1 Patient characteristics $(\mathrm{N}=68,976)$

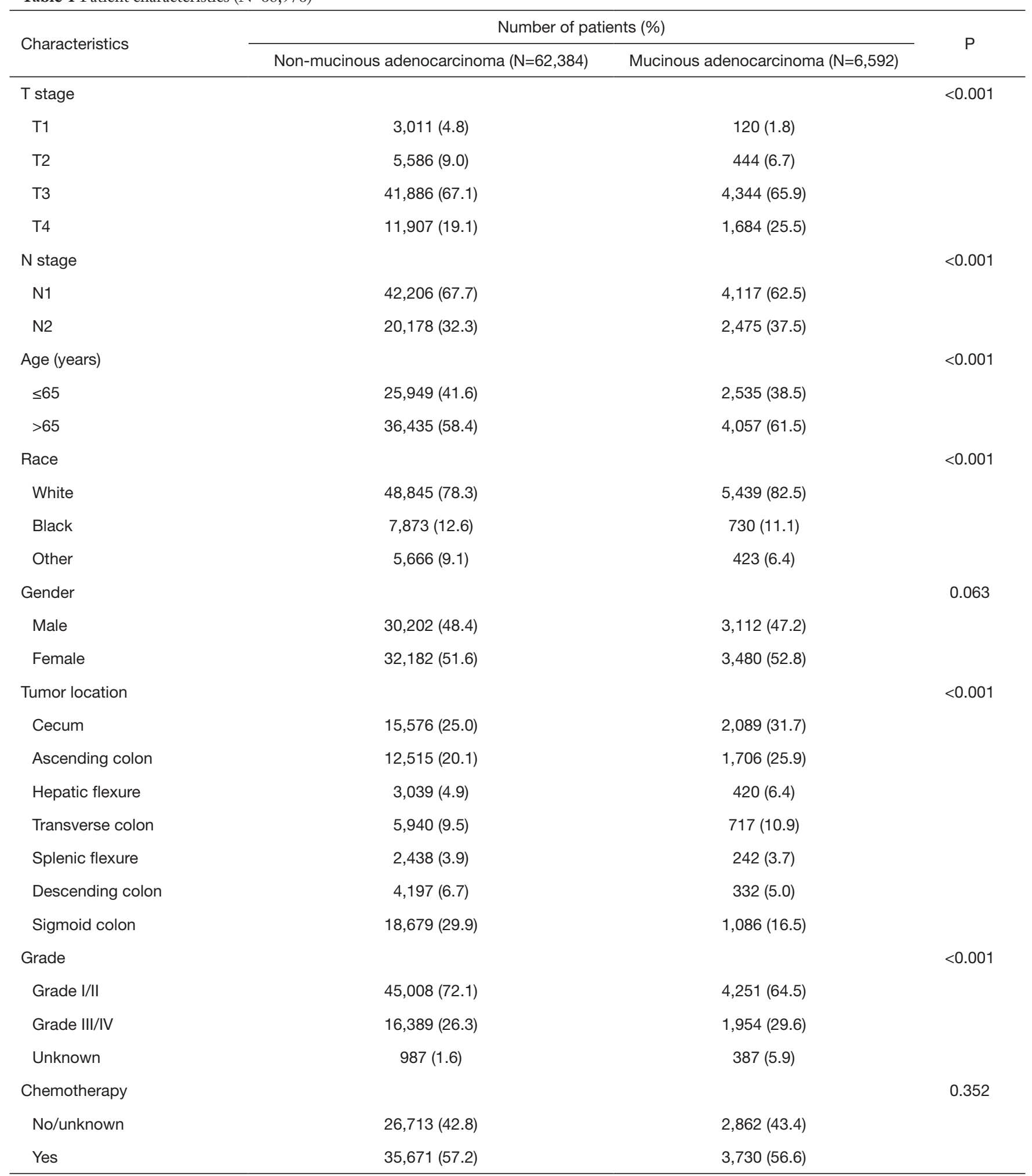



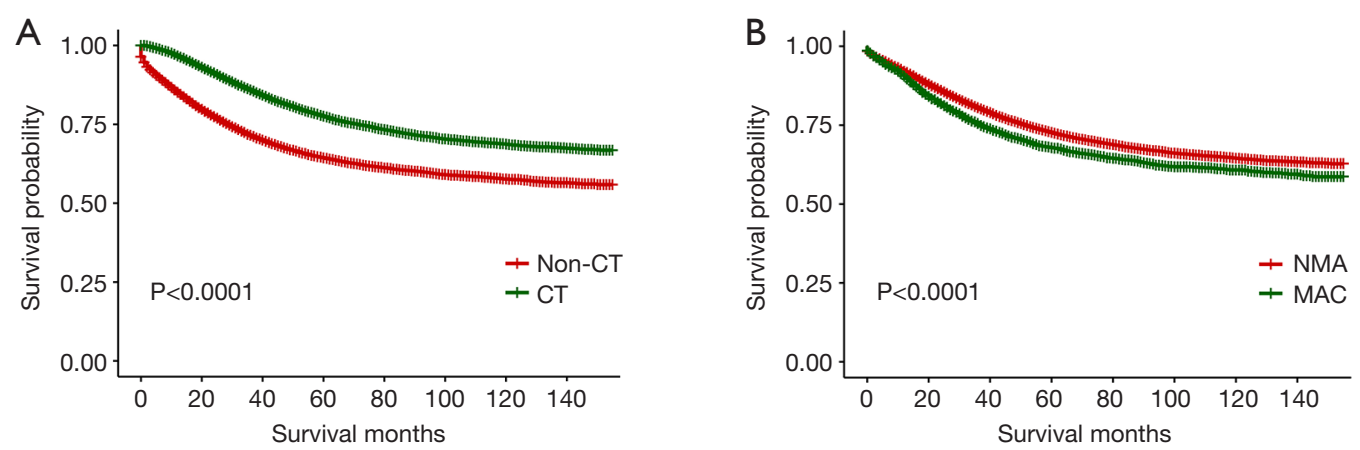

Figure 2 Kaplan-Meier curves of CSS in the whole cohort. (A) Treated with or without adjuvant chemotherapy (CT); (B) MAC or NMA. CSS, cancer-specific survival; MAC, mucinous adenocarcinoma; NMA, non-mucinous adenocarcinoma.
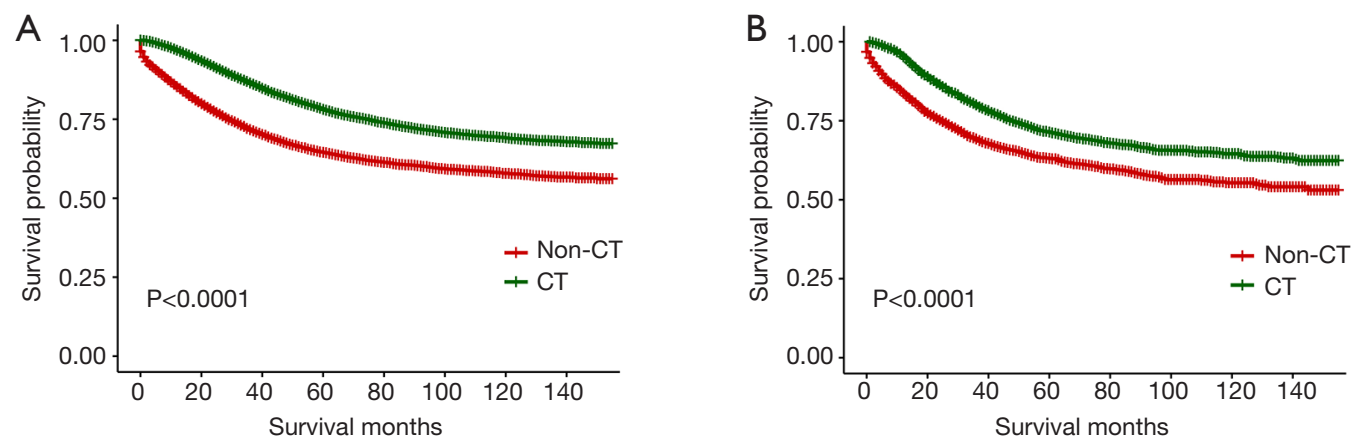

Figure 3 Kaplan-Meier curves of CSS according to the treatment with or without adjuvant chemotherapy. (A) In stage III non-mucinous colon cancer; (B) in stage III mucinous colon cancer. CSS, cancer-specific survival.

specific mortality compared to non-CT group in NMA ( $\mathrm{HR}=0.540,95 \%$ CI: 0.523-0.558, $\mathrm{P}<0.001$, Table 2$)$. In addition, higher $\mathrm{T}$ stage $(\mathrm{P}<0.001)$, higher $\mathrm{N}$ stage $(\mathrm{P}<0.001)$, older age $(\mathrm{P}<0.001)$, black race $(\mathrm{P}<0.001)$ and higher tumor grade $(\mathrm{P}<0.001)$ were also correlated with increased risk of colon cancer-specific mortality in NMA.

In MAC, $\mathrm{T}$ stage $(\mathrm{P}<0.001), \mathrm{N}$ stage $(\mathrm{P}<0.001)$, age $(\mathrm{P}<0.001)$, gender $(\mathrm{P}=0.061)$, tumor location $(\mathrm{P}=0.029)$, tumor grade $(\mathrm{P}<0.001)$ and the receipt of $\mathrm{CT}(\mathrm{P}<0.001)$ were subsequently incorporated into the multivariate analysis, which showed that the receipt of CT had 37.7\% independently decreased risk of colon cancer-specific mortality compared to non-CT group (HR $=0.623,95 \%$ CI: $0.566-0.685, \mathrm{P}<0.001$, Table 3). In addition, higher $\mathrm{T}$ stage $(\mathrm{P}<0.001)$, higher $\mathrm{N}$ stage $(\mathrm{P}<0.001)$, older age $(\mathrm{P}<0.001)$, male $(\mathrm{P}=0.042)$ and higher tumor grade $(\mathrm{P}<0.001)$ were also correlated with increased risk of colon cancer-specific mortality in MAC.

\section{The effect of histological subtype in patients with the receipt of $C T$}

To confirm the above findings about the survival difference in MAC and NMA with the receipt of CT to guide clinical treatment decision, patients with the receipt of CT were recruited for further Cox analyses.

In these patients, $\mathrm{T}$ stage $(\mathrm{P}<0.001), \mathrm{N}$ stage $(\mathrm{P}<0.001)$, age $(\mathrm{P}<0.001)$, gender $(\mathrm{P}<0.001)$, race $(\mathrm{P}<0.001)$, tumor location $(\mathrm{P}<0.001)$, tumor grade $(\mathrm{P}<0.001)$ and histological subtype $(\mathrm{P}<0.001)$ were subsequently incorporated into the multivariate analysis, which showed that the MAC was independently associated with $15.4 \%$ increased risk of colon cancer-specific mortality compared to NMA (HR $=1.154$, 95\% CI: 1.078-1.235, P<0.001, Table 4). Combined with the above results, it was found the increased risk of cancerspecific mortality of MAC compared to NMA was higher in patients with the receipt of CT $(15.4 \%)$ than in the whole cohort (5.6\%). 
Table 2 Factors associated with a CCSS in univariate and multivariate analyses in NMA

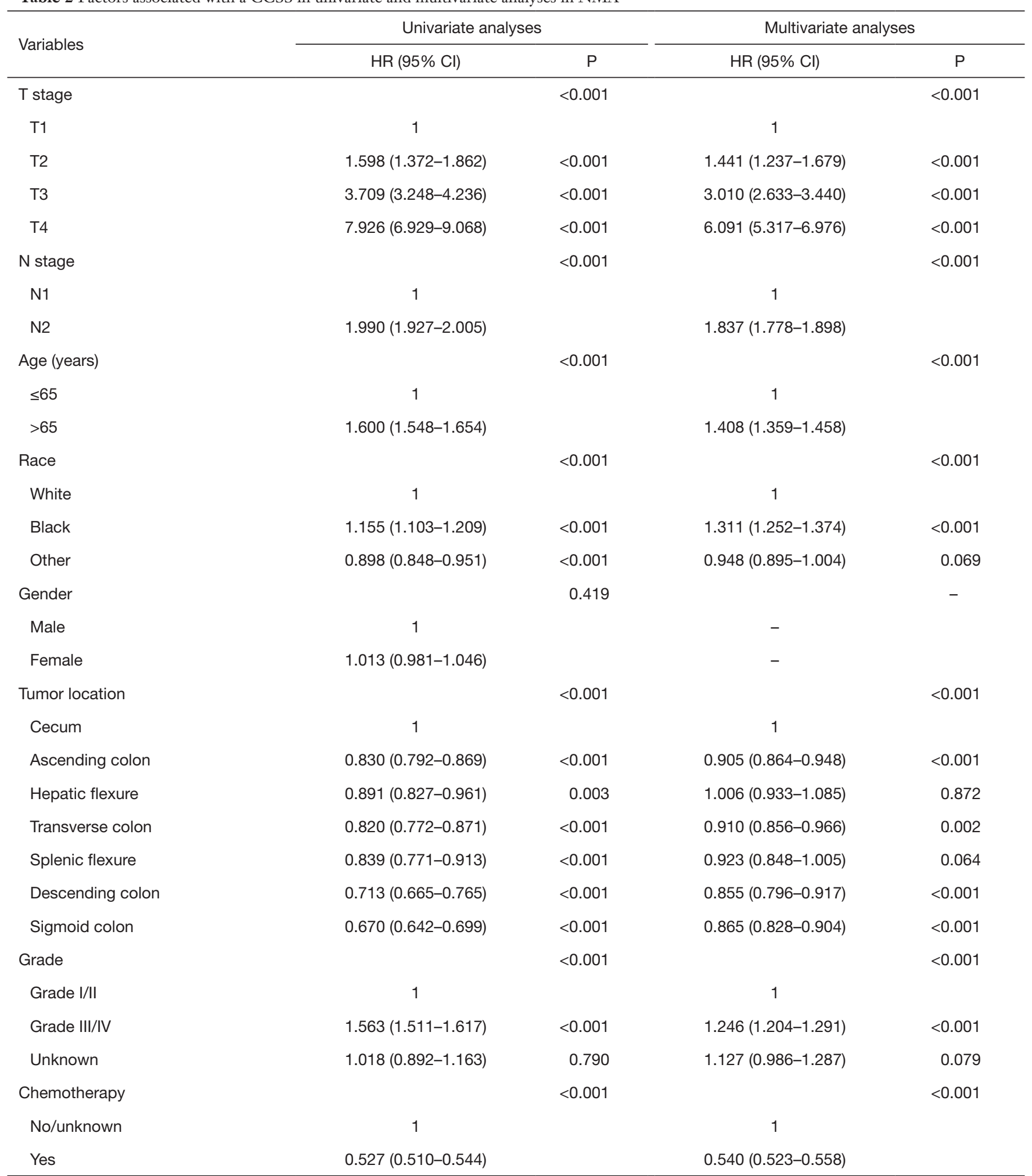

CCSS, colon cancer-specific survival; NMA, non-mucinous adenocarcinoma; HR, hazard ratio; Cl, confidence interval. 
Table 3 Factors associated with a CCSS in univariate and multivariate analyses in MAC

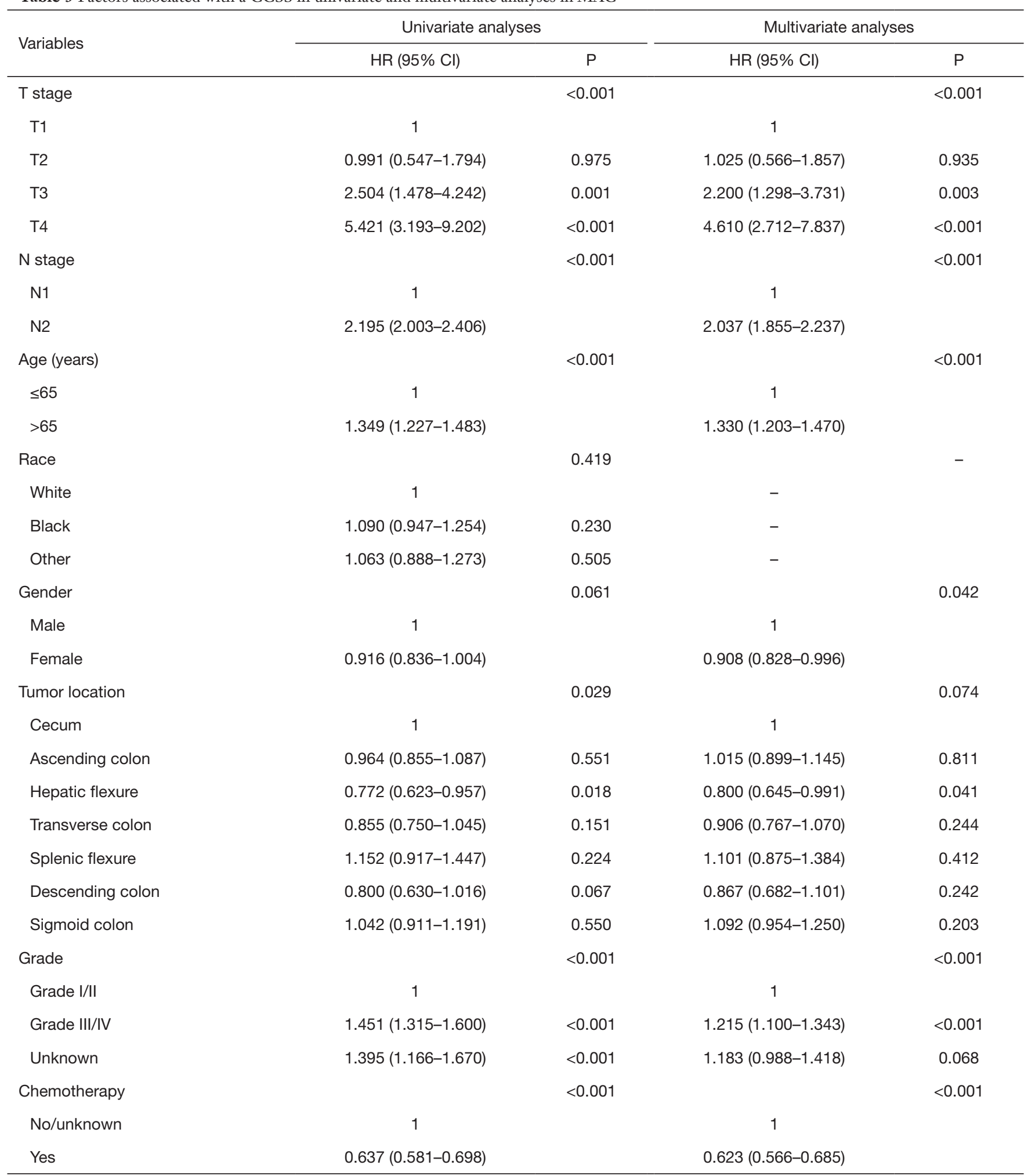

CCSS, colon cancer-specific survival; MAC, mucinous adenocarcinoma; HR, hazard ratio; $\mathrm{Cl}$, confidence interval. 
Table 4 Factors associated with a CCSS in univariate and multivariate analyses in patients with the receipt of CT

\begin{tabular}{|c|c|c|c|c|}
\hline Variables & \multicolumn{2}{|c|}{ Univariate analyses } & \multicolumn{2}{|c|}{ Multivariate analyses } \\
\hline T stage & & $<0.001$ & & $<0.001$ \\
\hline $\mathrm{T} 1$ & 1 & & 1 & \\
\hline T2 & $1.444(1.175-1.774)$ & $<0.001$ & $1.314(1.069-1.615)$ & 0.001 \\
\hline $\mathrm{T} 4$ & 7.727 (6.461-9.241) & $<0.001$ & $5.643(4.712-6.759)$ & $<0.001$ \\
\hline $\mathrm{N}$ stage & & $<0.001$ & & $<0.001$ \\
\hline $\mathrm{N} 1$ & 1 & & 1 & \\
\hline N2 & 2.247 (2.153-2.345) & & $1.943(1.860-2.029)$ & \\
\hline$>65$ & $1.201(1.151-1.253)$ & & $1.221(1.169-1.275)$ & \\
\hline Race & & $<0.001$ & & $<0.001$ \\
\hline White & 1 & & 1 & \\
\hline Black & $1.164(1.095-1.237)$ & $<0.001$ & $1.278(1.202-1.359)$ & $<0.001$ \\
\hline Other & 0.917 (0.850-0.989) & 0.025 & $0.967(0.896-1.043)$ & 0.382 \\
\hline Gender & & $<0.001$ & & $<0.001$ \\
\hline Male & 1 & & 1 & \\
\hline Female & $0.885(0.848-0.924)$ & & $0.864(0.827-0.901)$ & \\
\hline Splenic flexure & $0.826(0.737-0.927)$ & 0.001 & $0.887(0.791-0.996)$ & 0.042 \\
\hline Descending colon & $0.740(0.674-0.812)$ & $<0.001$ & $0.850(0.774-0.934)$ & 0.001 \\
\hline Sigmoid colon & $0.689(0.651-0.729)$ & $<0.001$ & $0.832(0.785-0.882)$ & $<0.001$ \\
\hline Grade & & $<0.001$ & & $<0.001$ \\
\hline Grade I/II & 1 & & 1 & \\
\hline Grade III/IV & $1.589(1.518-1.663)$ & $<0.001$ & $1.279(1.221-1.341)$ & $<0.001$ \\
\hline Unknown & $1.274(1.097-1.480)$ & 0.002 & $1.273(1.094-1.480)$ & 0.002 \\
\hline Histology & & $<0.001$ & & $<0.001$ \\
\hline Non-mucinous adenocarcinoma & 1 & & 1 & \\
\hline Mucinous adenocarcinoma & $1.331(1.245-1.423)$ & & $1.154(1.078-1.235)$ & \\
\hline
\end{tabular}

CCSS, colon cancer-specific survival; CT, chemotherapy; HR, hazard ratio; Cl, confidence interval. 
PSM was also used to investigate the effect of histological subtype in patients with the receipt of CT. In NMA, no significant differences were seen between non-CT and CT groups in all the patient characteristics after PSM $(\mathrm{P}>0.05$, Table S2), the receipt of CT was associated with $13.5 \%$ increased 5-year CSS rate compared to non-CT group (5-year CSS rates: $76.8 \%$ vs. $63.3 \%, \mathrm{P}<0.0001$; Figure S1A); in MAC, no significant differences were seen between non$\mathrm{CT}$ and $\mathrm{CT}$ groups in all the patient characteristics after PSM (P>0.05, Table S3), however, the receipt of CT had only $8.4 \%$ increased 5 -year CSS rate compared to non-CT group (5-year CSS rates: $71.0 \%$ vs. $62.6 \%, \mathrm{P}<0.0001$; Figure $S 1 B)$, which were consistent with the above findings.

\section{Discussion}

MAC was a rare histological type in colorectal cancer, it was reported to account for $10-20 \%$ of colorectal cancer patients. MAC was more common in the female, proximal colon and younger patients, and was more likely to be associated with advanced stages, high-degree microsatellite instability (MSH-H) and BRAF mutations $(8,13,20)$. Compared with the NMA, mucinous colon cancer also had a higher rate of peritoneal implantation and lymph node metastasis, and was characterized by a significantly larger maximal size $(21,22)$.

It was reported that transmembrane mucins and secreted mucins constituted the mucin family of human, and mucins could protect the epithelia by forming a mucus barrier. However, the mucin that gastrointestinal tract synthesized was not a single type, and one certain type of mucin might be dominantly expressed in one organ (23). According to previous research reports, mucin 2 and mucin $5 \mathrm{AC}$ might be related with the occurrence of colon MAC (24). Moreover, recent research showed that MUC2 and MUC5AC may become potential new targets for future treatment strategies of colon MAC in view of the different expression levels of them in MAC and NMA. However, up to now, the carcinogenesis mechanism was not entirely clear behind MUC2 and MUC5AC (13).

In spite of that the different gene expression and histology between NMA and MAC might suggest a different carcinogenesis mechanism, patients with mucinous colon cancer currently received treatments based on the standard treatment regimens of non-mucinous colon cancer and no specific clinical treatment guidelines had been developed for MAC (13,25-28).

In the current study, it was found that MAC was correlated with higher $\mathrm{T}$ stage and higher $\mathrm{N}$ stage, and was more likely to be found in cecum, ascending colon and hepatic flexure; the Kaplan-Meier survival analyses showed that the 5-year CSS rates of NMA and MAC were $72.7 \%$ and $67.9 \%$, respectively. In addition, the results of multivariate Cox analyses confirmed the worse prognosis of MAC when compared with NMA, which showed that MAC was independently associated with $5.6 \%$ increased risk of cancer-specific mortality compared with NMA. Few studies focused on the prognostic value of MAC in stage III colon cancer, and one recent research also found that MAC had $5.0 \%$ increased risk of mortality compared with NMA in stage III disease, which was similar to our finding (29). Although the survival difference between NMA and MAC achieved statistical difference in the present study, the magnitude of the difference was very small. It was therefore understandable that Catalano et al. (12) reported that mucinous histology did not show prognostic difference compared with NMA $(\mathrm{P}=0.5324)$ and the sample size of this study was very small with only 178 patients diagnosed with mucinous colon cancer included in this study.

More importantly, our study aimed to evaluate the efficacy of CT according to the histological type. In NMA, it was found that the 5-year CSS rates of CT group and non-CT group were $78.1 \%$ and $64.5 \%$, respectively; in MAC, the 5-year CSS rates of CT group and non-CT group were $71.3 \%$ and $63.1 \%$, respectively. After adjusting for other prognostic factors, results of multivariate Cox analyses showed that the receipt of CT was independently correlated with $46.0 \%$ decreased risk of colon cancerspecific mortality compared with non-CT group in NMA, and this number had fallen to $37.7 \%$ in MAC, indicating that MAC patients were less responsive to CT as compared to those with NMA. In addition, as a respective observational work, PSM was used to address potential bias in the present study, and the results also validated the above finding that $\mathrm{MAC}$ was less responsive to CT compared with NMA in stage III colon cancer.

To confirm the above findings about the survival difference between MAC and NMA with the receipt of CT to guide clinical treatment decisions, we then furtherly conducted Cox analyses in patients with the receipt of CT, and it was found that MAC was independently associated with $15.4 \%$ increased risk of colon cancer-specific mortality as compared with NMA.

Given that MAC was independently associated with only $5.6 \%$ increased risk of cancer-specific mortality as compared with NMA in the whole cohort, this result showed that the 
survival difference between MAC and NMA was amplified with the receipt of CT. The efficacy of adjuvant CT had been confirmed in stage III NMA, again, it demonstrated that MAC had reduced responsiveness to adjuvant CT, which was in agreement with previous reports (30-32).

However, Hugen and his colleagues (17) reported that the survival difference between MAC and NMA was not statistically significant in stage III disease with the receipt of adjuvant CT. We believed the different result from our study was probably because of the fact that multivariate analyses in their study had taken the rough staging system into account instead of the important $\mathrm{T}$ stage and $\mathrm{N}$ stage and their analyses were based on old AJCC TNM staging system which might miss N1c disease.

At a molecular level, this poor response of CT in MAC was attributed to the relative hypoxic state owing to a reduction in blood supply, and the histopathologic investigations showed that MAC had less micro-vessel density (MVD) than NMA, which might reduce the chemosensitivity because drug transport were closely related to tumor microcirculation (33-35).

Recently, with the analyses of 16,741 patients with stage III colon MAC, a large population-based study found that MAC with the receipt of CT was associated with $44 \%$ decreased risk of mortality as compared with NMA in stage III disease. However, the researchers of this study did not conduct a direct comparison survival benefit offered by CT between MAC and NMA (29).

To the best of our knowledge, aiming to guide clinicians in making treatment decisions in clinical practice, the current study was the first large population-based study to focus on stage III mucinous colon cancer and assess the efficacy of CT in stage III MAC with direct comparison with non-mucinous disease in recent years. Therefore, this study not only added to the body of evidence that the receipt of CT significantly improved the prognosis of stage III mucinous colon cancer, but also confirmed the reduced responsiveness to $\mathrm{CT}$ in MAC as compared with NMA. Stage III mucinous colon cancer still need to be treated with CT because of the significant survival benefit under the existing guidelines for colon cancer treatment. More importantly, however, the adjuvant treatment recommendations for stage III colon cancer should take histology into account, there was urgent need to develop individualized treatment programs for mucinous colon cancer in the future.

Two limitations in our analyses still need to be addressed. On the one hand, the SEER database had its inherent shortcomings, the lack of detailed clinicopathological factors including microsatellite instability, BRAF mutation, specific CT regimens, and tumor recurrence that might contribute to further exploration of the prognosis of MAC. On the other hand, it was a retrospective observational study, the biases inherent to the retrospective and nonrandomized nature of our analyses could not be completely removed, which might limit the conclusions that had be drawn, and the absence of prospective studies evaluating the efficacy of CT in stage III colon MAC required a cautious interpretation of our results.

In conclusion, MAC had minor worse prognosis and was less responsive to CT compared with NMA in stage III colon cancer. The survival difference was amplified with the receipt of CT. However, stage III mucinous colon cancer still need to be treated with CT because of the significant survival benefit and specialized treatment plans for MAC were quite necessary in the future.

\section{Acknowledgments}

Funding: None.

\section{Footnote}

Reporting Checklist: The authors have completed the STROBE reporting checklist. Available at http://dx.doi. org/10.21037/jgo-20-160

Conflicts of Interest: All authors have completed the ICMJE uniform disclosure form (available at http://dx.doi. org/10.21037/jgo-20-160). The authors have no conflicts of interest to declare.

Ethical Statement: The authors are accountable for all aspects of the work in ensuring that questions related to the accuracy or integrity of any part of the work are appropriately investigated and resolved. The study was conducted in accordance with the Declaration of Helsinki (as revised in 2013). This was a study using de-identified data from the SEER database. Ethical approval by the ethical committee of the Tongde Hospital of Zhejiang Province was waived based on our institutional policy. The SEER database is a free database, the data released by the SEER database did not require informed consent of patients.

Open Access Statement: This is an Open Access article distributed in accordance with the Creative Commons 
Attribution-NonCommercial-NoDerivs 4.0 International License (CC BY-NC-ND 4.0), which permits the noncommercial replication and distribution of the article with the strict proviso that no changes or edits are made and the original work is properly cited (including links to both the formal publication through the relevant DOI and the license). See: https://creativecommons.org/licenses/by-nc-nd/4.0/.

\section{References}

1. Siegel RL, Miller KD, Jemal A. Cancer statistics, 2020. CA Cancer J Clin 2020;70:7-30.

2. Hamilton SR, Aaltonen LA. editors. World Health Organization Classification of Tumours. Pathology and genetics of tumours of the digestive system. Lyon: IARC Press, 2000.

3. Catalano V, Loupakis F, Graziano F, et al. Mucinous histology predicts for poor response rate and overall survival of patients with colorectal cancer and treated with first-line oxaliplatin- and/or irinotecan-based chemotherapy. Br J Cancer 2009;100:881-7.

4. Börger ME, Gosens MJ, Jeuken JW, et al. Signet ring cell differentiation in mucinous colorectal carcinoma. J Pathol 2007;212:278-86.

5. Glasgow SC, Yu J, Carvalho LP, et al. Unfavourable expression of pharmacologic markers in mucinous colorectal cancer. Br J Cancer 2005;92:259-64.

6. Hugen $\mathrm{N}$, van Beek JJ, de Wilt JH, et al. Insight into mucinous colorectal carcinoma: clues from etiology. Ann Surg Oncol 2014;21:2963-70.

7. Leopoldo S, Lorena B, Cinzia A, et al. Two subtypes of mucinous adenocarcinoma of the colorectum: clinicopathological and genetic features. Ann Surg Oncol 2008;15:1429-39.

8. Green JB, Timmcke AE, Mitchell WT, et al. Mucinous carcinoma--just another colon cancer? Dis Colon Rectum 1993;36:49-54.

9. Kakar S, Aksoy S, Burgart LJ, et al. Mucinous carcinoma of the colon: correlation of loss of mismatch repair enzymes with clinicopathologic features and survival. Mod Pathol 2004;17:696-700.

10. Song GA, Deng G, Bell I, et al. Mucinous carcinomas of the colorectum have distinct molecular genetic characteristics. Int J Oncol 2005;26:745-50.

11. Ott C, Gerken M, Hirsch D, et al. Advanced Mucinous Colorectal Cancer: Epidemiology, Prognosis and Efficacy of Chemotherapeutic Treatment. Digestion 2018;98:143-52.
12. Catalano V, Loupakis F, Graziano F, et al. Prognosis of mucinous histology for patients with radically resected stage II and III colon cancer. Ann Oncol 2012;23:135-41.

13. Luo C, Cen S, Ding G, et al. Mucinous colorectal adenocarcinoma: clinical pathology and treatment options. Cancer Commun (Lond) 2019;39:13.

14. Twelves C, Wong A, Nowacki MP, et al. Capecitabine as adjuvant treatment for stage III colon cancer. $\mathrm{N}$ Engl J Med 2005;352:2696-704.

15. Lupinacci RM, Mello ES, Coelho FF, et al. Prognostic implication of mucinous histology in resected colorectal cancer liver metastases. Surgery 2014;155:1062-8.

16. Negri FV, Wotherspoon A, Cunningham D, et al. Mucinous histology predicts for reduced fluorouracil responsiveness and survival in advanced colorectal cancer. Ann Oncol 2005;16:1305-10.

17. Hugen N, Verhoeven RH, Radema SA, et al. Prognosis and value of adjuvant chemotherapy in stage III mucinous colorectal carcinoma. Ann Oncol 2013;24:2819-24.

18. Benson AB, Venook AP, Al-Hawary MM, et al. NCCN Guidelines Insights: Colon Cancer, Version 2.2018. J Natl Compr Canc Netw 2018;16:359-69.

19. Zhang Y, Guo Y, Zhou X, et al. Prognosis for different patterns of distant metastases in patients with uterine cervical cancer: a population-based analysis. J Cancer 2020;11:1532-41.

20. Kim SH, Shin SJ, Lee KY, et al. Prognostic value of mucinous histology depends on microsatellite instability status in patients with stage III colon cancer treated with adjuvant FOLFOX chemotherapy: a retrospective cohort study. Ann Surg Oncol 2013;20:3407-13.

21. Gruia C, Foarfa C, Streba L, et al. Synchronous carcinoma of the ascending colon and caecum. Rom J Morphol Embryol 2011;52:1369-75.

22. Nozoe T, Anai H, Nasu S, et al. Clinicopathological characteristics of mucinous carcinoma of the colon and rectum. J Surg Oncol 2000;75:103-7.

23. Betge J, Schneider NI, Harbaum L, et al. MUC1, MUC2, MUC5AC, and MUC6 in colorectal cancer: expression profiles and clinical significance. Virchows Arch 2016;469:255-65.

24. Pigny P, Guyonnet-Duperat V, Hill AS, et al. Human mucin genes assigned to $11 \mathrm{p} 15.5$ : identification and organization of a cluster of genes. Genomics 1996;38:340-52.

25. Imai $Y$, Yamagishi H, Fukuda K, et al. Differential mucin phenotypes and their significance in a variation of colorectal carcinoma. World J Gastroenterol 
2013;19:3957-68.

26. Hanski C. Is mucinous carcinoma of the colorectum a distinct genetic entity? Br J Cancer 1995;72:1350-6.

27. Hugen N, Simons M, Halilović A, et al. The molecular background of mucinous carcinoma beyond MUC2. J Pathol Clin Res 2014;1:3-17.

28. Weiss AA, Babyatsky MW, Ogata S, et al. Expression of MUC2 and MUC3 mRNA in human normal, malignant, and inflammatory intestinal tissues. J Histochem Cytochem 1996;44:1161-6.

29. Fields AC, Lu P, Goldberg J, et al. The role of adjuvant chemotherapy in stage II and III mucinous colon cancer. J Surg Oncol 2019;120:1190-200.

30. Maisano R, Azzarello D, Maisano M, et al. Mucinous histology of colon cancer predicts poor outcomes with FOLFOX regimen in metastatic colon cancer. J Chemother 2012;24:212-6.

31. McCawley N, Clancy C, O'Neill BD, et al. Mucinous Rectal Adenocarcinoma Is Associated with a Poor

Cite this article as: Yu F, Huang L, Shen F, Wu S, Chen J. Prognostic implications of mucinous histology in stage III colon cancer with the receipt of adjuvant chemotherapy. J Gastrointest Oncol 2020;11(5):858-869. doi: 10.21037/jgo-20-160
Response to Neoadjuvant Chemoradiotherapy: A Systematic Review and Meta-analysis. Dis Colon Rectum 2016;59:1200-8.

32. Napoletano M, Mazzucca D, Prosperi E, et al. Locally advanced rectal cancer: qualitative and quantitative evaluation of diffusion-weighted magnetic resonance imaging in restaging after neoadjuvant chemoradiotherapy. Abdom Radiol (NY) 2019;44:3664-73.

33. Oberholzer K, Menig M, Pohlmann A, et al. Rectal cancer: assessment of response to neoadjuvant chemoradiation by dynamic contrast-enhanced MRI. J Magn Reson Imaging 2013;38:119-26.

34. Höckel M, Knoop C, Schlenger K, et al. Intratumoral pO2 predicts survival in advanced cancer of the uterine cervix. Radiother Oncol 1993;26:45-50.

35. Thomlinson RH, Gray LH. The histological structure of some human lung cancers and the possible implications for radiotherapy. Br J Cancer 1955;9:539-49. 


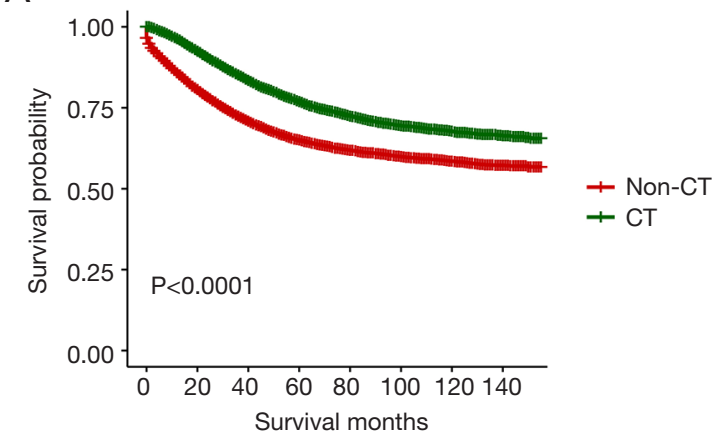

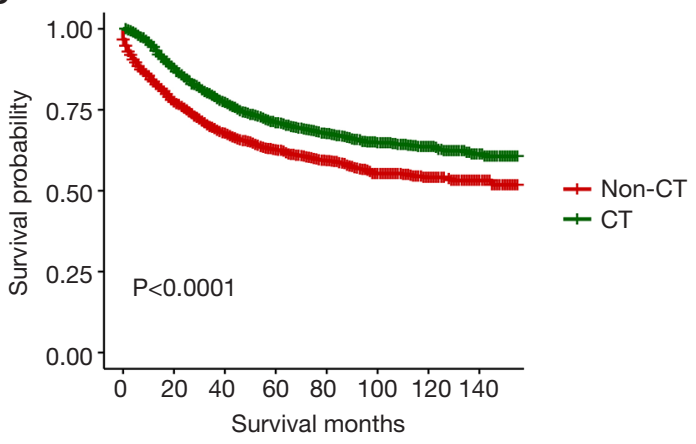

Figure S1 Kaplan-Meier curves of CSS after propensity score matching. (A) In stage III nonmucinous colon cancer; (B) in stage III mucinous colon cancer. CT, chemotherapy.

Table S1 Factors associated with a CCSS in univariate and multivariate analyses in the whole cohort

\begin{tabular}{|c|c|c|c|c|}
\hline \multirow{2}{*}{ Variables } & \multicolumn{2}{|c|}{ Univariate analyses } & \multicolumn{2}{|c|}{ Multivariate analyses } \\
\hline & $\mathrm{HR}(95 \% \mathrm{Cl})$ & $\mathrm{P}$ & $\mathrm{HR}(95 \% \mathrm{Cl})$ & $P$ \\
\hline T stage & & $<0.001$ & & $<0.001$ \\
\hline $\mathrm{T} 1$ & 1 & & 1 & \\
\hline $\mathrm{T} 2$ & $1.562(1.347-1.811)$ & $<0.001$ & 1.419 (1.224-1.645) & $<0.001$ \\
\hline T3 & $3.653(3.212-4.155)$ & $<0.001$ & $2.967(2.607-3.377)$ & $<0.001$ \\
\hline $\mathrm{T} 4$ & $7.845(6.887-8.937)$ & $<0.001$ & $6.043(5.300-6.891)$ & $<0.001$ \\
\hline $\mathrm{N}$ stage & & $<0.001$ & & $<0.001$ \\
\hline N1 & 1 & & 1 & \\
\hline N2 & 2.017 (1.957-2.078) & & $1.858(1.802-1.917)$ & \\
\hline Age (years) & & $<0.001$ & & $<0.001$ \\
\hline$\leq 65$ & 1 & & 1 & \\
\hline$>65$ & $1.574(1.526-1.624)$ & & $1.400(1.354-1.447)$ & \\
\hline Race & & $<0.001$ & & $<0.001$ \\
\hline White & 1 & & 1 & \\
\hline Black & $1.146(1.097-1.197)$ & $<0.001$ & $1.294(1.238-1.352)$ & $<0.001$ \\
\hline Other & $0.905(0.857-0.956)$ & $<0.001$ & $0.956(0.905-1.010)$ & 0.112 \\
\hline Gender & & 0.839 & & - \\
\hline Male & 1 & & - & \\
\hline Female & $1.003(0.973-1.034)$ & & - & \\
\hline Tumor location & & $<0.001$ & & $<0.001$ \\
\hline Cecum & 1 & & 1 & \\
\hline Ascending colon & $0.846(0.810-0.883)$ & $<0.001$ & $0.919(0.880-0.960)$ & $<0.001$ \\
\hline Hepatic flexure & $0.876(0.816-0.941)$ & $<0.001$ & $0.979(0.912-1.051)$ & 0.561 \\
\hline Transverse colon & $0.827(0.781-0.875)$ & $<0.001$ & $0.911(0.861-.956)$ & 0.001 \\
\hline Splenic flexure & $0.868(0.802-0.939)$ & $<0.001$ & $0.943(0.871-1.021)$ & 0.147 \\
\hline Descending colon & $0.719(0.672-0.769)$ & $<0.001$ & $0.860(0.803-0.920)$ & $<0.001$ \\
\hline Sigmoid colon & $0.688(0.661-0.717)$ & $<0.001$ & $0.883(0.847-0.921)$ & $<0.001$ \\
\hline Grade & & $<0.001$ & & $<0.001$ \\
\hline Grade I/II & 1 & & 1 & \\
\hline Grade III/IV & $1.556(1.507-1.607)$ & $<0.001$ & $1.244(1.204-1.286)$ & $<0.001$ \\
\hline Unknown & $1.172(1.055-1.302)$ & 0.003 & $1.157(1.040-1.286)$ & 0.007 \\
\hline Histology & & $<0.001$ & & 0.030 \\
\hline Non-mucinous adenocarcinoma & 1 & & 1 & \\
\hline Mucinous adenocarcinoma & $1.207(1.150-1.267)$ & & $1.056(1.005-1.109)$ & \\
\hline Chemotherapy & & $<0.001$ & & $<0.001$ \\
\hline No/unknown & 1 & & 1 & \\
\hline Yes & $0.538(0.522-0.554)$ & & $0.549(0.532-0.567)$ & \\
\hline
\end{tabular}

CCSS, colon cancer-specific survival; HR, hazard ratio; $\mathrm{Cl}$, confidence interval. 
Table S2 Patient characteristics in stage III NMA after PSM

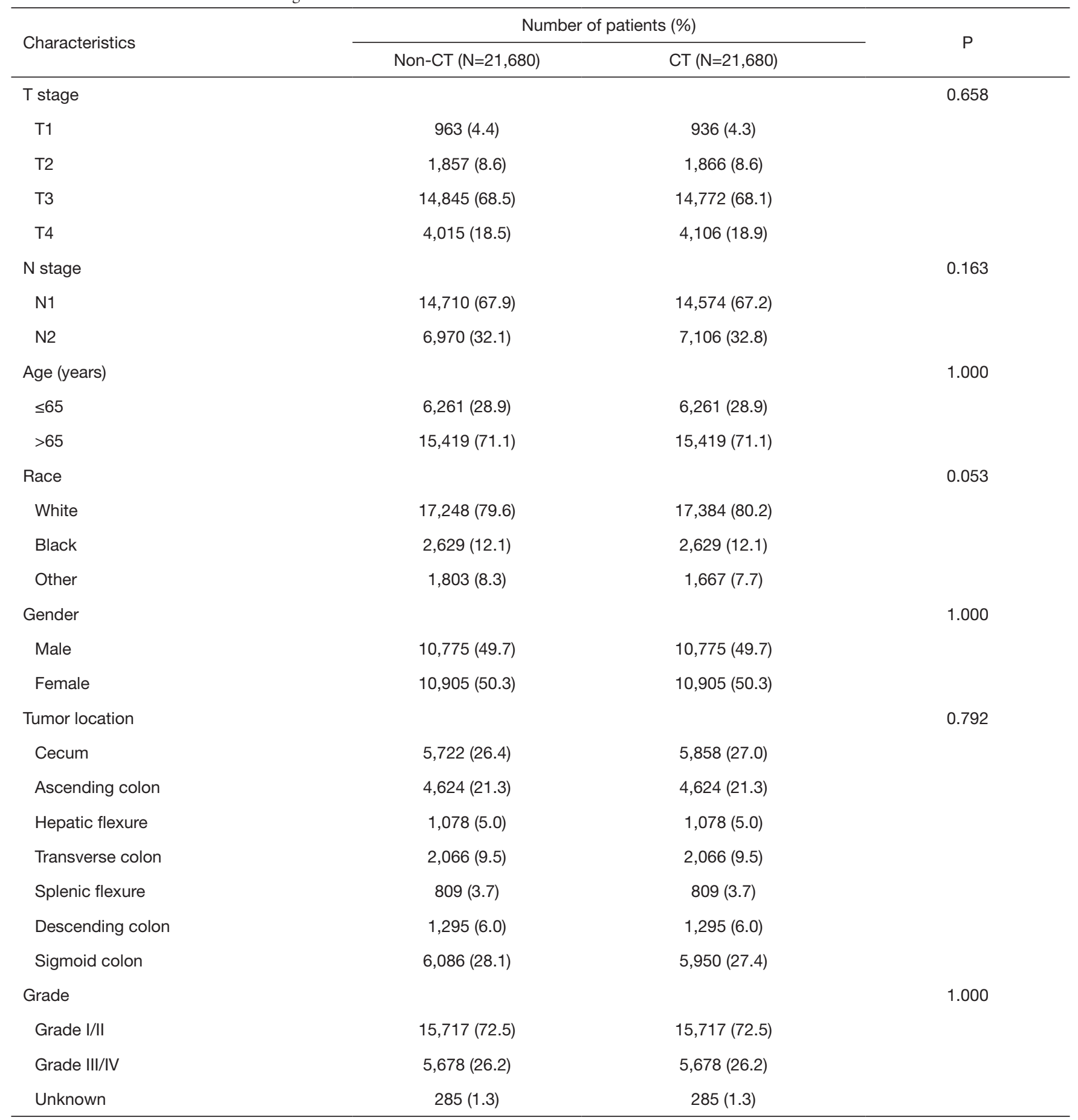

NMA, non-mucinous adenocarcinoma; PSM, propensity score matching; CT, chemotherapy. 
Table S3 Patient characteristics in stage III MAC after PSM

\begin{tabular}{|c|c|c|c|}
\hline Characteristics & \multicolumn{2}{|c|}{ Number of patients (\%) } & $\mathrm{P}$ \\
\hline T stage & & & 0.149 \\
\hline $\mathrm{T} 1$ & $41(1.8)$ & $50(2.1)$ & \\
\hline T2 & $155(6.7)$ & $191(8.2)$ & \\
\hline $\mathrm{T} 4$ & $590(25.3)$ & $591(25.4)$ & \\
\hline $\mathrm{N}$ stage & & & 0.277 \\
\hline N1 & $1,463(62.8)$ & $1,427(61.3)$ & \\
\hline N2 & 866 (37.2) & $902(38.7)$ & \\
\hline$>65$ & $1,745(74.9)$ & 1,745 (74.9) & \\
\hline Race & & & 0.731 \\
\hline White & $1,930(82.9)$ & 1,928 (82.8) & \\
\hline Black & $247(10.6)$ & $259(11.1)$ & \\
\hline Other & $152(6.5)$ & $142(6.1)$ & \\
\hline Gender & & & 0.860 \\
\hline Male & $1,085(46.6)$ & $1,079(46.3)$ & \\
\hline Female & $1,244(53.4)$ & $1,250(53.7)$ & \\
\hline Splenic flexure & $103(4.4)$ & $92(4.0)$ & \\
\hline Descending colon & $106(4.6)$ & $122(5.2)$ & \\
\hline Sigmoid colon & $345(14.8)$ & $321(13.8)$ & \\
\hline Grade & & & 0.163 \\
\hline Grade I/II & $1,519(65.2)$ & $1,475(63.3)$ & \\
\hline Grade III/IV & 681 (29.2) & $738(31.7)$ & \\
\hline Unknown & $129(5.5)$ & $116(5.0)$ & \\
\hline
\end{tabular}

MAC, mucinous adenocarcinoma; PSM, propensity score matching; CT, chemotherapy. 